Origical Article

\title{
Pre-Emptive Analgesic Effect of Intravenous Paracetamol in Modified radical mastectomy
}

\author{
Bhawana Wagle ${ }^{1}$, Yogesh Regmi ${ }^{1}$, Sudhir Shrestha ${ }^{1}$, Pradeep Thapa ${ }^{1}$, Suraj VishowKarma ${ }^{1}$, Megh Raj
} Mandal $^{1}$, Sujan Kandel ${ }^{1}$, Sumit Singh ${ }^{1}$, Deepak Mauni ${ }^{2}$ Durga Khanal $^{3}$

${ }^{1}$ Department of Anaesthesia, ${ }^{2}$ Department of Surgical Oncology, Breast Unit, BPKMCH, ${ }^{3}$ Department of Nursing, BPKMCH

\begin{abstract}
Background: Modified radical mastectomy (MRM) is associated with significant post-operative pain. Intravenous (iv) paracetamol provides pain relief in most patients who have undergone MRM. It has been observed from previous studies conducted on patients undergoing other surgeries like abdominal surgeries that the analgesic efficacy of iv paracetamol improves when used Pre-emptively. There are no studies done previously on use of iv paracetamol Pre-emptively in MRM.

Objective: The purpose of the study was to determine the post-operative analgesic effects of Pre-emptive intravenous (iv) paracetamol in MRM.

Materials and Methods: Following institutional ethics committee approval, fourty American Society of Anesthesiology (ASA) physical status I-II patients were assigned in a randomized manner into two groups: Group I received iv paracetamol $1 \mathrm{~g}$, in $100 \mathrm{~mL}, 15$ minutes before induction and Group II received iv paracetamol $1 \mathrm{~g}$, in $100 \mathrm{~mL}$, at the end of the surgery. The time to first analgesic use and the total analgesic consumed in 24 hours was recorded. Visual Analog Scale (VAS) pain scores were obtained from all patients at 0, 30 minutes, 1, 2, 6, 12 and 24 hours after the end of the Surgery.

Results: Time to first analgesic requirement was significantly longer in Group I compared to Group II ( $p=0.0329)$. Rescue analgesic consumption and post-operative VAS pain scores recorded were significantly lower in Group I compared to Group II ( $p<0.05)$ until 24 after surgery.

Conclusion: Pre-emptive iv paracetamol in comparison to intra- operative paracetamol, provided effective and reliable post- operative analgesia after modified radical mastectomy.
\end{abstract}

Keywords: Medical Record Section, BPKMCH, Geographical Variation, GB Cancer Burden, Terai, Nepal

\section{Introduction}

A modified radical mastectomy is a procedure in which the entire breast is removed, including the skin, areola, nipple, and most axillary lymph nodes; the pectoralis major muscle is spared. Historically, a modified radical mastectomy was the primary method of treatment of breast cancer. ${ }^{1}$

Modified radical mastectomy is associated with moderate to sever post-operative pain, which is related to surgical trauma [2]. Routine analgesic treatment is usually based on opioid or non-opioid analgesics with rescue opioids $[2,3]$.

Pre-emptive pain control is where, regional or systemic analgesics are applied before the start of the surgical procedure. The affect is achieved by suppressing, either together or separately, central or peripheral sensitization. Pre-emptive analgesia gives rise to a subsiding pain model, a decrease in analgesic requirements, and a decline in morbidity, promoting wellness and shortening the length of hospital stays [4-6]. However, opinions on the utility of pre-emptive analgesia differ between observers [6,7].

Paracetamol (acetaminophen; N-acetyl-p-aminophenol) is one of the most regularly used drugs worldwide, attributable to an excellent safety profile of the drug. Paracetamol inhibits both isoforms of cyclo-oxygenase (COX); COX-1 and COX-2 and it also reinforces descending serotonergic inhibitory pain pathways [8].

Correspondence

Dr Bhawana Wagle, HOD, Anaesthesia Department, BPKMCH.

Tel No: 9845197649. E-Mail: bit2wagle@yahoo.com 
The pre- emptive effect of intravenous paracetamol has been studied in various surgical procedures. While some study suggested that iv paracetamol is effective as a pre-emptive analgesic [9] others find no credibility [10]. Even though there are studies to show that intravenous paracetamol provides good analgesia in other surgeries [8,11-13] there has been no study to study the pre- emptive effect of paracetamol in these surgeries. The purpose of the present study was to determine the post-operative analgesic effects of pre-emptive iv paracetamol and the amount of reduction in opioid consumption in MRM.

\section{Materials \& Methods}

Ethical clearance was obtained by the ethical committee of B.P. Koirala memorial cancer hospital. After obtaining written informed consent from each participant, patients in the age group of $16-69$ years, undergoing MRM, were enrolled. The inclusion criteria were ASA physical status I and II, not having any contraindications to the use of the study drug. Patients of age more than 70 years; having history of central nervous system disorders, impaired renal functions, impaired liver function, patients $20 \%$ more or less than the ideal body weight, history of allergic reactions to paracetamol and patients on chronic analgesic treatment were excluded. Patients were seen on the day before surgery and trained about the usage of the VAS for pain scores. The VAS represents the simple verbal scale and evaluates pain according to the following scores: $0=$ no pain; $10=$ excruciating pain.

\section{STUDY DESIGN}

The study was single center, randomized, double-blind study. A total of 2 anesthetists were involved in the study. All the patients were allocated in one of these two groups using the serial number. Coin was tossed to decide the group in which the first patient fall. Coin tossed head for group 1 and tail for group 2. The next patient thereafter allocated in the other group. Primary investigator and the patient were blinded to the study drugs. Assessment of the patient prior to, during and after the procedure and operation was done by the blinded primary investigator. Drugs were given by the second investigator who tossed the coin for randomization.

Group I patients $(\mathrm{n}=20)$ received iv paracetamol $1 \mathrm{~g}, 15$ minutes prior to induction. In Group II ( $\mathrm{n}=20)$, iv paracetamol $1 \mathrm{~g}$ was given at the end of the surgery. In the operating room, Electrocardiogram (ECG), Non-Invasive Blood Pressure (NIBP), Heart Rate (HR), and Peripheral
Oxygen Saturation (SpO2) were monitored.

Anaesthetic technique was standardized. The patients were preoxygenated for 3 minutes with $100 \%$ oxygen. For induction and intubation, $2 \mathrm{mg} / \mathrm{kg}$ propofol, $2 \mu \mathrm{g} /$ $\mathrm{kg}$ fentanyl citrate, and $0.8 \mathrm{mg} / \mathrm{kg}$ vecuronium were given. Following intubation, maintenance of general anaesthesia was accomplished by providing isoflurane in 100 oxygen and, if required, $0.2 \mathrm{mg} / \mathrm{kg}$ vecuronium. Patients were extubated when fully awake. All the patients were transferred to Post Anaesthesia Care Unit (PACU).

Post-operative pain was assessed at recovery room till the first hour of surgery and then at the patient's rooms. VAS pain scores were recorded at 0,30 th minutes and 1 , $2,6,12,18$, and 24 hours after the completion of surgery. Patients of both groups received iv tramadol $1.5 \mathrm{mg} / \mathrm{kg}$ of starting dose and the same dose was repeated with a maximum dose of $400 \mathrm{mg}$ daily. inj ondensetrone $4 \mathrm{mg}$ iv eight hourly given to all the patient. The time for first analgesic requirement was noted. Total consumption of tramadol was noted. Side effects if any, such as nausea, vomiting, respiratory depression, itching, rash, allergic reaction and hypotensions were recorded.

The data were analyzed using SPSS software. ANOVA, Kruskal Wallis test, Chi square test and different tables and diagrams were used in proper context in the process of data analysis.

P-values $<0.05$ were considered significant. Data are presented as mean values and standard deviation (mean \pm $\mathrm{SD})$.

\section{Result}

Both groups were comparable with regard to demographic variables (age, gender and weight), ASA physical status and the mean duration of surgery time.

Table-1 Demographic properties and duration of surgery

\begin{tabular}{|l|l|l|}
\hline & Group 1 & Group 2 \\
\hline Age (year) & $40.7(9.24)$ & $43.9(7.58)$ \\
\hline Gender M/F & $12 / 8$ & $11 / 8$ \\
\hline ASA I/II & $17 / 3$ & $17 / 2$ \\
\hline Weight (kg) & $48.67(9.68)$ & $49.90(9.46)$ \\
\hline $\begin{array}{l}\text { Duration of surgery } \\
\text { (minutes) }\end{array}$ & $111.60(15.33)$ & $\begin{array}{l}109.83 \\
(12.58)\end{array}$ \\
\hline
\end{tabular}

The changes in post-operative VAS pain scores are shown in [Table - 2]. Mean VAS pain scores recorded at 15, 30 minutes, 1, 2 and 6 hours were higher in Group II, compared to Group I $(\mathrm{P}<0.05)$. 
Table 2: Mean VAS pain scores

\begin{tabular}{|l|l|l|l|l|l|l|l|}
\hline Groups & 0 mins & $\mathbf{3 0}$ mins & $\mathbf{1}$ hrs & $\mathbf{2}$ hrs & $\mathbf{6}$ hrs & $\mathbf{1 2}$ hrs & $\mathbf{2 4}$ hrs \\
\hline $\begin{array}{l}\text { Group I } \\
(\mathrm{n}=20)\end{array}$ & $\begin{array}{l}1.9 \\
(0.9)\end{array}$ & $\begin{array}{l}2.0 \\
(1.4)\end{array}$ & $\begin{array}{l}2.5 \\
(1.2)\end{array}$ & $\begin{array}{l}2.5 \\
(0.6)\end{array}$ & $\begin{array}{l}1.8 \\
(1.5)\end{array}$ & $\begin{array}{l}3.6 \\
(1.6)\end{array}$ & $\begin{array}{l}1.4 \\
(0.9)\end{array}$ \\
\hline $\begin{array}{l}\text { Group II } \\
(\mathrm{n}=19)\end{array}$ & $\begin{array}{l}2.9 \\
(1.1)\end{array}$ & $\begin{array}{l}3.1 \\
(1.9)\end{array}$ & $\begin{array}{l}3.6 \\
(1.9)\end{array}$ & $\begin{array}{l}(0.0 \\
(0.9)\end{array}$ & $\begin{array}{l}2.7 \\
(1.2)\end{array}$ & $\begin{array}{l}3.9 \\
(1.8)\end{array}$ & $\begin{array}{l}1.7 \\
(1.1)\end{array}$ \\
\hline
\end{tabular}

\begin{tabular}{|l|l|l|l|l|l|l|l|}
\hline p-value & 0.0036 & 0.0459 & 0.0362 & 0.0474 & 0.0463 & 0.7156 & 0.3562 \\
\hline
\end{tabular}

Time to first request analgesic was significantly longer in Group I compared to Group II $(\mathrm{P}=0.0329)$ [Table-3]. The total consumed dose of tramadol during the post-operative 24 hours was significantly less in Group I $(\mathrm{P}=0.0141)$ when compared to Group II.

Table 3: First analgesia requirement time, postoperative total consumption of tramadol

\begin{tabular}{|l|l|l|l|}
\hline & Group 1 & Group 2 & p-value \\
\hline $\begin{array}{l}\text { First analgesic requirement } \\
\text { time (minutes) }\end{array}$ & $\begin{array}{l}193.6 \\
(36.8)\end{array}$ & $\begin{array}{l}164 \\
(46.3)\end{array}$ & 0.0329 \\
\hline $\begin{array}{l}\text { Total tramadol } \\
\text { consumption }\end{array}$ & 166 & 197 & 0.0141 \\
\hline $\begin{array}{l}\text { Data expressed as } \\
\text { mean (SD). Statistically } \\
\text { significant if p }<0.05 .\end{array}$ & & $(44.79)$ & \\
\hline
\end{tabular}

Post-operative side effects of the cases are shown in [Table4]. Incidence of nausea and vomiting was similar in both the groups. About 30\% patients developed nausea in Group I whereas in Group II it was 26\%. About $10 \%$ patients had vomiting in group I whereas the incidence was $15 \%$ in group II. No other side effects were recorded in either of the groups.

\section{Table 4: Side effects}

\begin{tabular}{|l|l|l|}
\hline & Group 1 & Group 2 \\
\hline Nausea & $6(30)$ & $5(26)$ \\
\hline Vomiting & $2(10)$ & $3(15)$ \\
\hline Itching & - & - \\
\hline Respiratory depression & - & - \\
\hline Hypotension & - & - \\
\hline Allergic reaction & - & - \\
\hline $\begin{array}{l}\text { Data expressed as mean } \\
\text { (SD). Statistically significant } \\
\text { if } p<0.05 .\end{array}$ & & \\
\hline
\end{tabular}

\section{Discussion}

Despite widespread use for over five decades, the mechanism of action of paracetamol is still unclear. Current evidence points to inhibition of prostaglandin synthesis (cyclooxygenase (COX) inhibition), and interaction with both serotonergic and cannabinoid pathways. Non-steroidal Anti-inflammatory Drugs (NSAIDs) also act by inhibition of COX, yet important differences exist; notably, paracetamol displays weak anti-inflammatory activity, few or no gastrointestinal side effects, and only a small dose-dependent alteration of platelet function [7]. Two systematic reviews have found the rate of adverse events following administration of paracetamol is not significantly different to that following administration of placebo $[14,15]$. The onset and duration of paracetamol's analgesic action is determined to a large extent by the route of administration. Intravenous administration will achieve therapeutic plasma concentrations within 20 minutes of an initial dose, and concentrations remain therapeutic for around 2 hours post dose [16]. . On literature search, we found no studies on paracetamol being used as a pre-emptive analgesic in modified radical mastectomy (MRM).

Pre-emptive analgesia means that an analgesic intervention is started before the noxious stimulus arises in order to block peripheral and central nociception. This afferent blockade of nociceptive impulses is maintained throughout the intra-operative and post-operative period. The goals of pre-emptive analgesia are, first, to decrease acute pain after tissue injury, second, to prevent pain-related pathologic modulation of the central nervous system, and third, to inhibit the persistence of post-operative pain and the development of chronic pain [6].

Intravenous paracetamol has been used as a pre-emptive analgesic in various other surgeries $[8,9,10,11,13]$. Arici and colleagues [8] have found that preemptively administered iv paracetamol $1 \mathrm{~g}$ in patients undergoing a total abdominal hysterectomy operation had no negative effects on intra-operative or post-operative hemodynamic parameters, ensured an effective analgesia during the post-operative period, increased patient satisfaction by reducing post-operative morphine consumption and side effects, and thereby shortened the length of hospital stay. In our study, we have similarly found that paracetamol $1 \mathrm{~g}$ given pre-operatively ensures effective analgesia and reduces total analgesic consumption.

Toygar and colleagues studied the pre-emptive analgesic effect of intravenous paracetamol in lumbar disk surger- 
ies [9]. Similar to our study they administered paracetamol $1 \mathrm{~g} 15$ mins prior to the induction (group I) and in another group paracetamol $1 \mathrm{~g}$ was given at the end the surgery (group II). Even though the VAS pain scores and total morphine consumption (delivered through patient controlled analgesia) was lower in group I, the difference was not statistically significant.

Amin SM and colleagues have compared the efficacy of pre-emptive gabapentin and paracetamol in adenotonsillectomies [11]. They found premptive gabapentin to be more efficacious compared to paractemol, but unlike our study they used oral paracetamol. While oral bioavailability is good (63-89\%), early plasma concentrations following oral administration may vary, and in some cases concentrations may remain subtherapeutic for a significant period [8]. Also, there may be a large variation in individual levels, as found in a previous study [17].

In another study, [17] 300 patients, posted for laparoscopic cholecystectomy were grouped into pre-emptive and post-operative paracetamol groups and the analgesic efficacy was compared with a placebo group. Similar to our study, they found that time to first analgesic requirement was significantly longer in the pre-emptive. Total analgesic consumption and post-operative VAS pain scores recorded were significantly lower in the group in which paracetamol was pre-emptively used.

In our study, the time first analgesic requirement was significantly longer in Group I $(\mathrm{P}=0.0329)$. We believe that pre-emptively delivered paracetamol in group I prevented central sensitization, so its analgesic effect continued longer than its effect period. This is substantiated by the fact that the VAS scores recorded in the immediate post-operative period till the 12th hour are significantly lower. The VAS scores recorded were lower in every time frame till the 12 th hour.This led to reduced tramadol consumption in the first 24 hours. The reduction in total tramadol consumption may also be due to the opioid sparing effect of pre-emptive paracetamol which has been seen in other studies as well $[8,17]$.

Adverse effects of tramadol, nausea in particular, are dose- dependent and therefore considerably more likely to appear if the loading dose is high [18]. In our patients initial VAS scores were lower in Group I compared to Group II. Hence we believe that use of pre-emptive paracetamol can reduce the loading dose of tramadol. The reduction of this dose during the first days of treatment is an important factor in improving tolerability. The most common adverse effects of tramadol are nausea, vomit- ing, dizziness, fatigue, sweating, dry mouth, drowsiness and orthostatic hypotension [19]. In our patients, only nausea and vomiting were observed. The incidence of side effects was equal in both the groups. Even though number of patients who experienced these side effects was similar, patients in Group II experienced more episodes of nausea and vomiting and required greater dose of rescue antiemetic. There were no observed episodes of respiratory depression or hypotension. This was possibly because no patient in either group received tramadol in excess of maximum daily dose of $400 \mathrm{mg}$.

\section{Conclusion}

Our findings indicate that pre-emptively administered iv paracetamol $1 \mathrm{~g}$ in patients undergoing MRM ensures an effective analgesia during the post-operative period, increases the time to first analgesic requirement and reduces opioid consumption. Therefore, we believe that in comparison to paracetamol $1 \mathrm{~g}$ administered intra- operatively, paracetamol administered pre-emptively can provide better analgesia in the post-operative period in modified radical mastectomy.

\section{References}

1. History of surgery for breast cancer: radical to the sublime.Curr Surg. 2003; 60(3):329-37 (ISSN: 01497944)

2. Dolin SJ, Cashman JN, Bland JM. Effectiveness of acute post-operative pain management: I. Evidence from published data. Br J Anaesth. 2002;89:409-23. Wall PD.

3. The prevention of post-operative pain. Pain. 1988;33:289-90.

4. Dahl JB, Kehlet H. The value of pre-emptive analgesia in the treatment of post- operative pain. $\mathrm{Br} \mathrm{J}$ Anaesth. 1993; 70: 434-9.

5. Grape $S$, Tramèr MR. Do we need pre-emptive analgesia for the treatment of post-operative pain? Best Pract Res Clin Anaesthesiol. 2007;21:51-63. 6. Kayhan Z. Post-operative pain and control. Klinik Anestezi: Logos Publishing. 2005; 643-8.

7. Oscier CD and Milner QJW. Peri-operative use of paracetamol. Anaesthesia. 2009; 64: 65-72.

8. Arici S, Gurbet A, Türker G, Yavaşcaoşlu B, Sahin S. Pre-emptive analgesic effects of intravenous paracetamol in total abdominal hysterectomy. Agri. 2009 Apr; 21(2): 54-61.

9. Toygar P, Akkaya T, Ozkan D, Ozel O, Uslu E, Gümüş 
H. Does iv paracetamol have pre-emptive analgesic effect on lumber disc surgeries? Agri. 2008; 20(2): 14-9.

10. Kemppainen T, Kokki H, Tuomilehto H, Seppä J and Nuutinen J. Acetaminophen is highly effective in pain treatment after endoscopic sinus surgery. The Laryngoscope. 2006; 116: 2125-28.

11. Amin SM, Amr YM. Comparison between pre-emptive gabapentin and paracetamol for pain control after adenotonsillectomy in children. Anesth Essays Res. 2011;5:167-70

12. Barden J, Edwards J, Moore A, McQuay H. Single dose oral paracetamol (acetaminophen) for post-operative pain. Cochrane Database of Systematic Reviews. 2004; 1: CD004602.

13. Weil K, Hooper L, Afzal Z, et al. Paracetamol for pain relief after surgical removal of lower wisdom teeth. Cochrane Database of Systematic Reviews. 2007; 3: CD004487.

14. Graham G, Scott K, Day RO. Tolerability of paracetamol. Drug Safety. 2005; 28: 227-40.
15. Flouvat B, Leneveu A, Fitoussi S, Delhotal-Landes B, Gendron A. Bioequivalence study comparing a new paracetamol solution for injection and propacetamol after single intravenous infusion in healthy subjects. International Journal of Clinical Pharmacology and Therapeutics. 2004; 42: 50-7.

16. Holmer-Pettersson P, Owall A, Jakobsson J. Early bioavailability of paracetamol after oral or intravenous administration. Acta Anaesthesiologica Scandanavica. 2004; 48: 867-70.

17. Arslan, Mustafa, et al. "Comparing the efficacy of pre-emptive intravenous paracetamol on the reducing effect of opioid usage in cholecystectomy." Journal PArtICUlArS oF ContrIBUtorS: of Research in Medical Sciences. 2013;18.3.

18. Dayer P, Desmeules J, Collart L. Pharmacology of tramadol. Drugs. 1997;53 Suppl 2:18-24. Review.

19. Leppert W. Tramadol as an analgesic for mild to moderate cancer pain. Pharmacol Rep. 2009; 61(6): 978-92. 